\title{
Cis-Lunar Reusable In-Space Transportation Architecture for the Evolvable Mars Campaign
}

\author{
Eric S. McVay ${ }^{1}$, Christopher A. Jones ${ }^{2}$, and Raymond G. Merrill ${ }^{3}$ \\ NASA Langley Research Center, Hampton, VA 23681
}

\begin{abstract}
Human exploration missions to Mars or other destinations in the solar system require large quantities of propellant to enable the transportation of required elements from Earth's sphere of influence to Mars. Current and proposed launch vehicles are incapable of launching all of the requisite mass on a single vehicle; hence, multiple launches and in-space aggregation are required to perform a Mars mission. This study examines the potential of reusable chemical propulsion stages based in cis-lunar space to meet the transportation objectives of the Evolvable Mars Campaign and identifies cis-lunar propellant supply requirements. These stages could be supplied with fuel and oxidizer delivered to cis-lunar space, either launched from Earth or other inner solar system sources such as the Moon or near Earth asteroids. The effects of uncertainty in the model parameters are evaluated through sensitivity analysis of key parameters including the liquid propellant combination, inert mass fraction of the vehicle, change in velocity margin, and change in payload masses. The outcomes of this research include a description of the transportation elements, the architecture that they enable, and an option for a campaign that meets the objectives of the Evolvable Mars Campaign. This provides a more complete understanding of the propellant requirements, as a function of time, that must be delivered to cis-lunar space. Over the selected sensitivity ranges for the current payload and schedule requirements of the 2016 point of departure of the Evolvable Mars Campaign destination systems, the resulting propellant delivery quantities are between 34 and 61 tonnes per year of hydrogen and oxygen propellant, or between 53 and 76 tonnes per year of methane and oxygen propellant, or between 74 and 92 tonnes per year of hypergolic propellant. These estimates can guide future propellant manufacture and/or delivery architectural analysis.
\end{abstract}

\section{Nomenclature}

$\begin{array}{ll}\mathrm{CP} & =\text { Chemical Propulsion } \\ \Delta \mathrm{V} & =\text { Change in Velocity } \\ \text { DDT\&E } & =\text { Design, Development, Testing, and Evaluation } \\ \text { EDL } & =\text { Entry Descent and Landing } \\ \text { EMC } & =\text { Evolvable Mars Campaign } \\ \text { EOI } & =\text { Earth Orbit Insertion } \\ \text { HIAD } & =\text { Hypersonic Inflatable Aerodynamic Decelerator } \\ \text { IMF } & =\text { Inert Mass Fraction } \\ \text { I }_{\text {sp }} & =\text { Specific Impulse } \\ \text { ISS } & =\text { International Space Station } \\ \text { ISRU } & =\text { In-Situ Resource Utilization } \\ \text { LCH } & =\text { Liquid Methane } \\ \text { LDHEO } & =\text { Lunar Distance High-Earth Orbit } \\ \text { LDRO } & =\text { Lunar Distant Retrograde Orbit } \\ \text { LEO } & =\text { Low-Earth Orbit } \\ \text { LGA } & =\text { Lunar Gravity Assist } \\ \text { LH } & \end{array}$

${ }^{1}$ Aerospace Engineer, Space Mission Analysis Branch, MS 462, AIAA Member.

2 Aerospace Engineer, Space Mission Analysis Branch, MS 462, AIAA Member.

${ }^{3}$ Aerospace Engineer, Space Mission Analysis Branch, MS 462, AIAA Senior Member. 


$\begin{array}{ll}\text { LOX } & =\text { Liquid Oxygen } \\ \text { MMH } & =\text { Monomethylhydrazine } \\ \text { MOI } & =\text { Mars Orbit Insertion } \\ \text { MTV } & =\text { Mars Transit Vehicle } \\ \text { NEA } & =\text { Near-Earth Asteroid } \\ \text { NASA } & =\text { National Aeronautics and Space Administration } \\ \text { NTO } & =\text { Nitrogen Tetroxide } \\ \text { PEV } & =\text { Phobos Exploration Vehicle } \\ \text { SLS } & =\text { Space Launch System } \\ \text { SOI } & =\text { Sphere of Influence } \\ \text { TEI } & =\text { Trans-Earth Injection } \\ \text { TMI } & =\text { Trans-Mars Injection } \\ \text { TOF } & =\text { Time of Flight }\end{array}$

\section{Introduction}

$\mathrm{T}$

HE Evolvable Mars Campaign (EMC) is an ongoing series of architectural trade analyses to define the capabilities and elements needed for a sustainable human presence on the surface of Mars. The Human Exploration and Operations Mission Directorate leads the campaign, with participation across nine NASA centers, and close coordination with other architectural analysis groups, the Science and Space Technology Mission Directorates and the Offices of the Chief Scientist and the Chief Technologist. The EMC routinely invites inputs from external organizations as well, including international partners, industry, academia, and NASA advisory groups ${ }^{1}$.

The EMC identifies a set of operational capabilities and architectural trades required to sustainably expand human presence from low-Earth orbit (LEO) into deep space. The capability-driven EMC integrates science missions, robotic precursors, capability pathfinders, and a sustainable cadence of crewed missions and activities that can lead to an extended human presence on the surface of Mars. This cadence of missions includes test demonstrations that advance common capability developments across the architecture that can support a sustainable human presence on the surface of Mars.

Several scenarios have been considered for a human mission to the surface of Mars. Of these, only one spans all Mars vicinity destinations. The "Mars vicinity and Phobos, followed by mission to Mars surface" scenario represents an ambitious campaign that leverages most of the capabilities and potential tradeoffs described in the EMC. It acts as a point of comparison for future assessments and serves as the baseline reference for the EMC. This baseline scenario is then used to evaluate capabilities, schedules, risks, challenges, and mitigation strategies. To provide focus and to limit the possible alternatives, a set of ground rules and constraints were initially applied:

- Humans will travel to the Mars System by mid-2030s.

- The International Space Station (ISS) will operate through at least 2024 - until a regular cadence of Space Launch System (SLS)/Orion missions to cis-lunar space is established. The Mars-class life support and related habitation systems will be tested first on ISS.

- The SLS Block 2 launch vehicle will be available (4xRS25 Core + Exploration Upper Stage (EUS) + Evolved Boosters $+8.4 \mathrm{~m}$ or $10 \mathrm{~m}$ fairing) for Mars missions.

- The Orion spacecraft will be available.

- The SLS/Orion launch rate of one per year is sustainable in the Proving Ground Phase 1 and will increase to one cargo and one crew launch per year in preparation for the Mars mission system validation.

- In-space propulsion technology will utilize solar electric propulsion systems extensible from the Asteroid Redirect Mission's robotic spacecraft bus, augmented with chemical systems when necessary.

- Mars vehicle checkout and aggregation will be conducted in cis-lunar space to leverage infrastructure established during Proving Ground missions in the 2020s.

- Human missions to the Mars system will be developed for four crew members.

- Crew vehicle and transportation systems will be reused for sustainability and potential cost advantages when reasonable.

The assumed use of in-space solar electric propulsion poses several challenges to a long-term, reusability compatible architecture. The performance of the solar arrays degrades over time, such that reuse over a fifteen year period for a proposed hybrid spacecraft leads to significant reductions in available power ${ }^{2}$. Current solar electric propulsion systems utilize xenon as their propellant; however, the proposed campaign in the EMC requires large quantities of xenon relative to Earth's commercial productive capability ${ }^{3}$. The effectiveness of solar electric propulsion 
decreases further from the sun, requiring larger arrays. Thus, an alternative in-space transportation architecture for the Evolvable Mars Campaign, using chemical propulsion and propellant transfer, allows for a comparison of different capability paths on the journey to Mars.

Previous studies have identified the potential for the intersection of chemical propulsion, in-space storage, and propellant transfer to enable missions to $\mathrm{Mars}^{4-7}$. These studies have considered the application of those three capabilities to supporting Mars missions similar to the Design Reference Architecture 5.0 ${ }^{8}$. The Evolvable Mars Campaign, however, has a different set of destinations and missions, which drive the requirements on the in-space transportation system. This paper develops a chemical propulsion in-space transportation architecture to meet that cadence of missions, and can be used to inform future studies of propellant delivery options to cis-lunar space.

\section{Concept of Operations}

A reusable transportation architecture that operates roundtrip between cis-lunar space and Mars for delivery of piloted and cargo EMC payloads has been developed. The resulting propellant demand required in cis-lunar space, specifically lunar distant retrograde orbit (LDRO), to support EMC objectives has been determined. For this analysis the following assumptions were used:

- propulsion systems are entirely chemical propulsion $(\mathrm{CP})$

- all propulsion stages are returned to cis-lunar space and reused

- there is a single common stage size, with partially filled stages used when necessary

- the campaign follows a split-mission style for both cargo and piloted missions

- lossless propellant storage and transfer is possible in cis-lunar space

A top level diagram of a roundtrip mission from cis-lunar space to Mars is depicted in Figure 1.

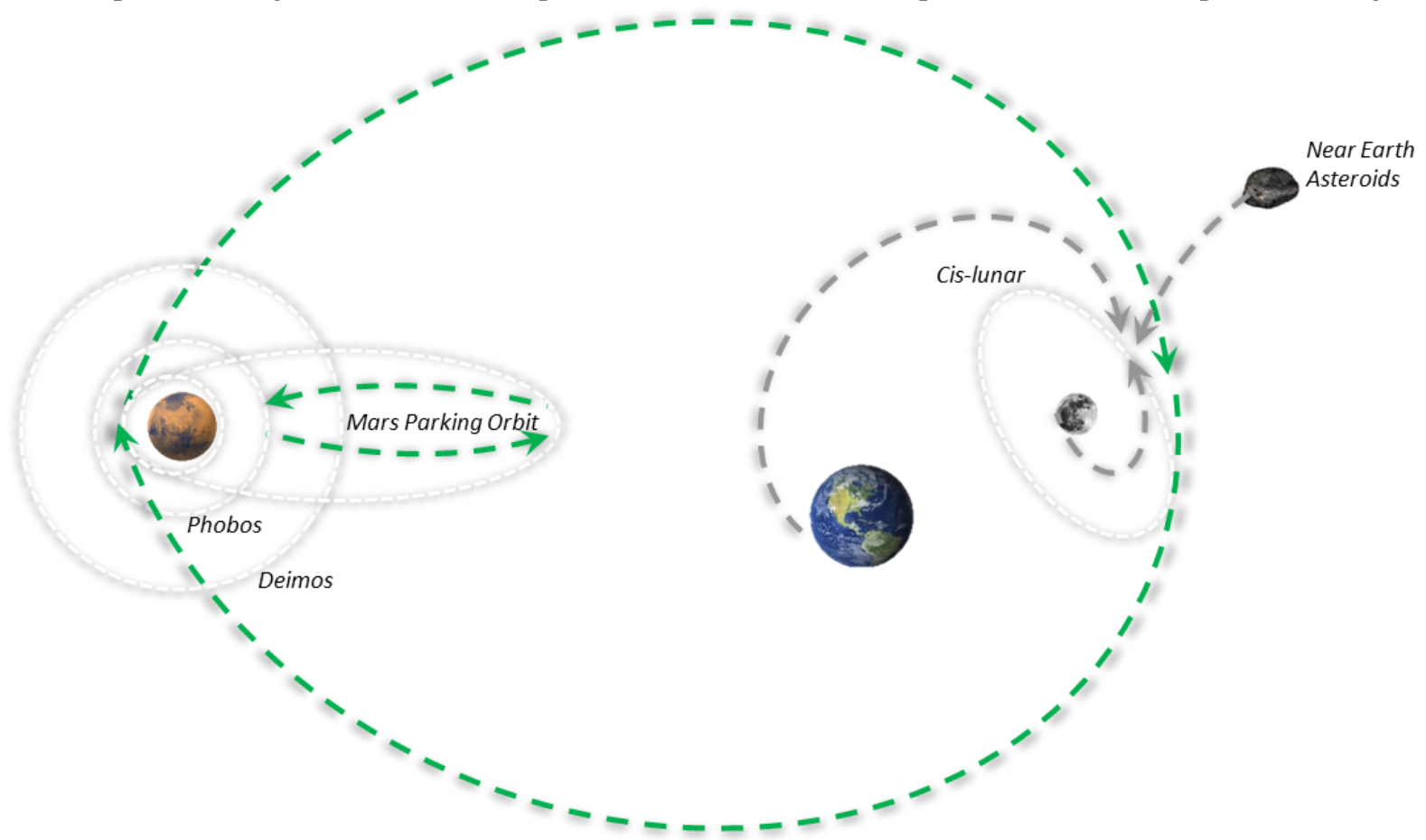

Figure 1. Roundtrip Mission from Cis-Lunar Space to the Martian SOI

Flight elements and systems are delivered, assembled, and evaluated in the stable, low-energy LDRO. The Mars transit vehicle (MTV) then completes a low-energy maneuver to transfer to lunar distance high-Earth orbit (LDHEO), where the crew (via Orion delivered by the SLS) rendezvous with and boards the MTV. After checkout, the Orion is left in LDHEO to return to Earth, and the MTV departs for Mars. Upon arriving into the Mars parking orbit (1-Sol period) the piloted stack rendezvous with the chemical stage needed for return to Earth and either a taxi or lander; the crew then departs for their destination mission (either to Phobos, Deimos, or the surface of Mars). After their destination mission is complete the crew returns to the in-space transportation system and begins their transfer to Earth. Upon arrival at Earth the MTV recaptures into a LDHEO similar to that used for departure and rendezvous with a 
predeployed Orion spacecraft, which returns the crew to Earth. The MTV then completes a low-energy transfer to LDRO and is refurbished and resupplied for the next mission. The time between trans-Mars injection (TMI) and Earth orbit insertion (EOI) is approximately 1000 days for all three crewed opportunities examined in the EMC, in 2033, 2039 , and 2043 . The total change in velocity $(\Delta \mathrm{V})$ ranges between $2,800 \mathrm{~m} / \mathrm{s}$ and $3,400 \mathrm{~m} / \mathrm{s}$ for crewed and cargo missions.

The point of departure EMC mars mission cadence is a crewed mission either every 2 Mars transfer opportunities, or every three for the first surface mission to allow time for additional lander delivery. For all mission sets, the cargo is deployed before or concurrent with the crew. Figure 2 shows the concept of operations for the 2033 crewed mission to Phobos including the 2031 cargo pre-deploy mission.

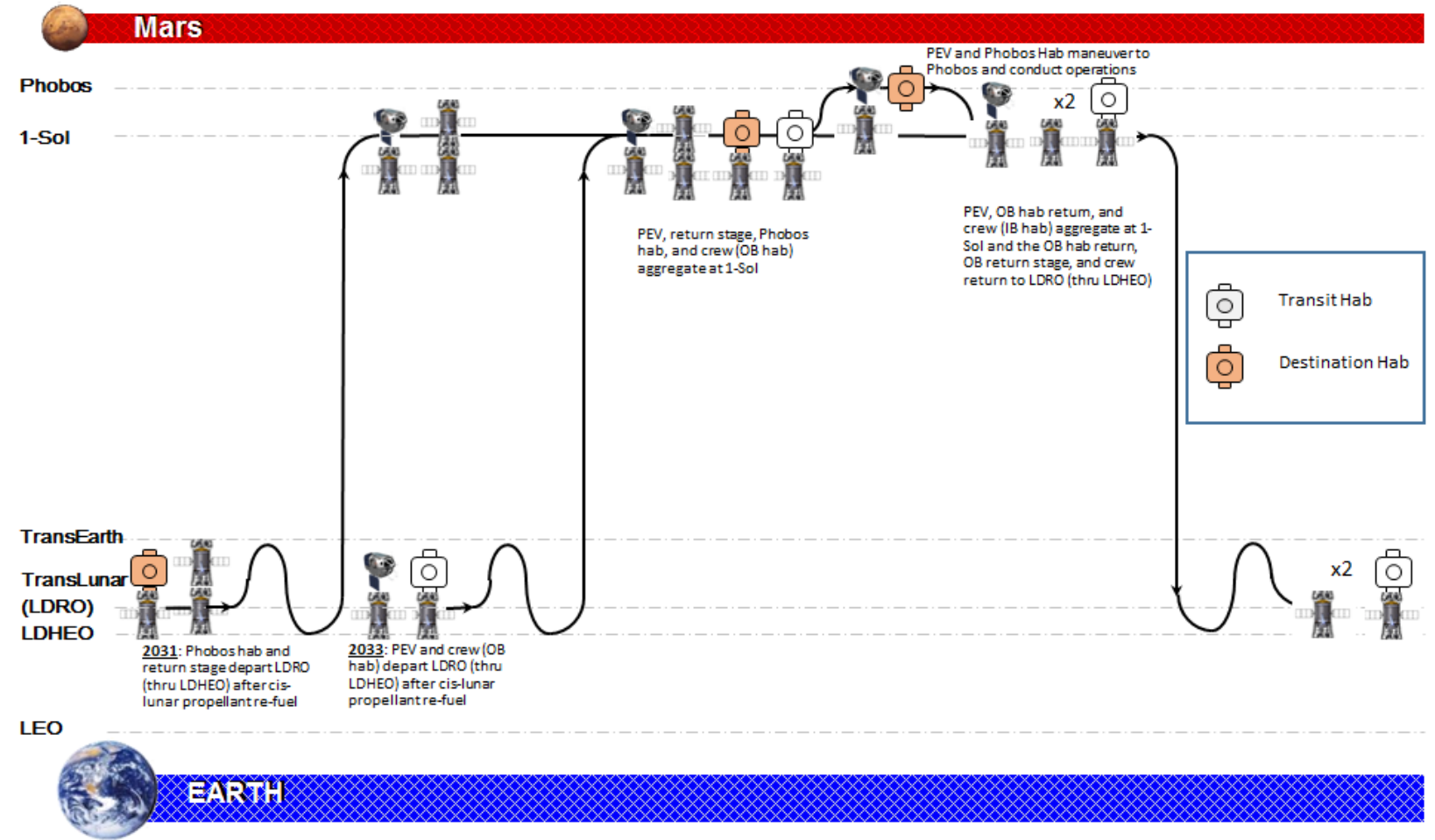

Figure 2. Concept of Operations for 2033 Crewed Phobos Mission

The Phoboshabitat and the transit habitat return stage are deployed to a 1-Sol Mars parking orbit in 2031. In 2033, the Phobos exploration vehicle (PEV) and transit habitat (crew) depart cis-lunar space and aggregate with the predeployed cargo in the Mars parking orbit. The PEV and Phobos habitat (crew) then transfer to Phobos and conduct mission operations, while the transit habitat reorients itself and prepares for departure. Upon completion of the destination mission, the crew transfer back to the transit habitat in the PEV. The transit habitat (with crew) and transit habitat outbound return stage then depart the Mars parking orbit, return to Earth and capture back into LDHEO for crew return to Earth to cis-lunar space. The un-crewed habitat then returns to cis-lunar space (LDRO) where the vehicles are prepared for their next mission. 


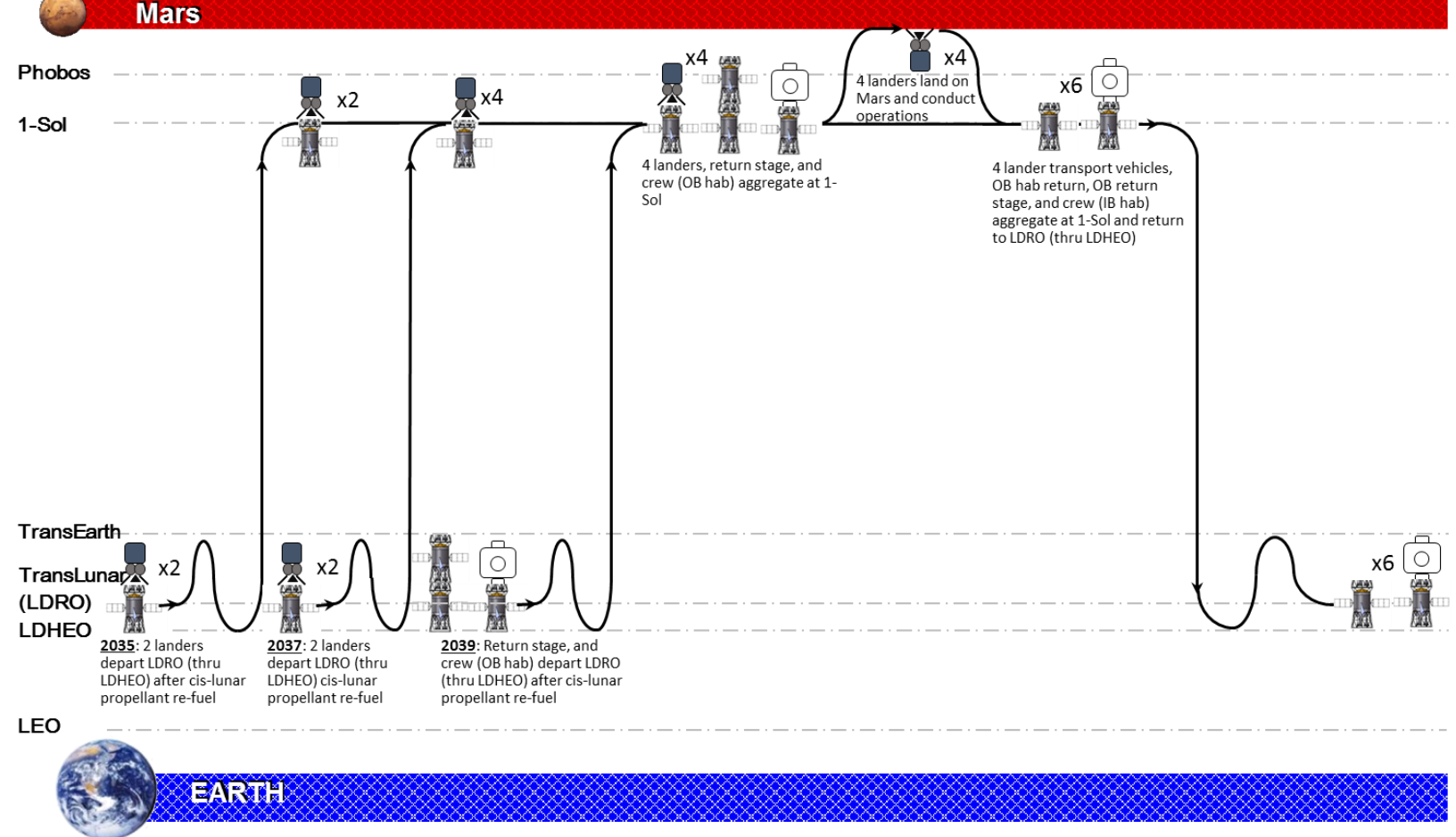

Figure 3 shows the concept of operations for the 2039 crewed mission to the surface of Mars, including the 2035 and 2037 cargo missions. Two landers are transferred from Cis-lunar to a 1-Sol Mars parking orbit in each of 2035 and 2037 (four total landers). The landers are launched to cis-lunar space, where they rendezvous with the stages that deliver them to Mars. The chemical stage performs Earth departure and at Mars close approach captures the lander into a 1-sol Mars orbit, where they are dropped off. The crew descent lander is captured and remains at the 1-Sol Mars parking orbit for the crew, while the other three landers descend to the surface of Mars in advance of the crewed mission. This allows for surface system checkout and verification and provides an added mission and an safety assurance mechanism before the crew depart Earth's SOI.

An alternate lander deployment option exists in which the landers aerocapture into the Mars parking orbit and the delivery vehicle completes a flyby and returns to Earth, but for the current EMC hypersonic inflatable aerodynamic decelerator (HIAD) based lander system this requires significant increase (6-7 tonnes) in lander thermal protection system mass for a second inflatable aerodynamic decelerator for landers that have long loiters, specifically the lander than the crew descend in. No trade study was performed between the aerocapture and chemical capture concepts at this point as the lander with two HIAD systems cannot be launched to cis-lunar space with the assumed SLS performance. 


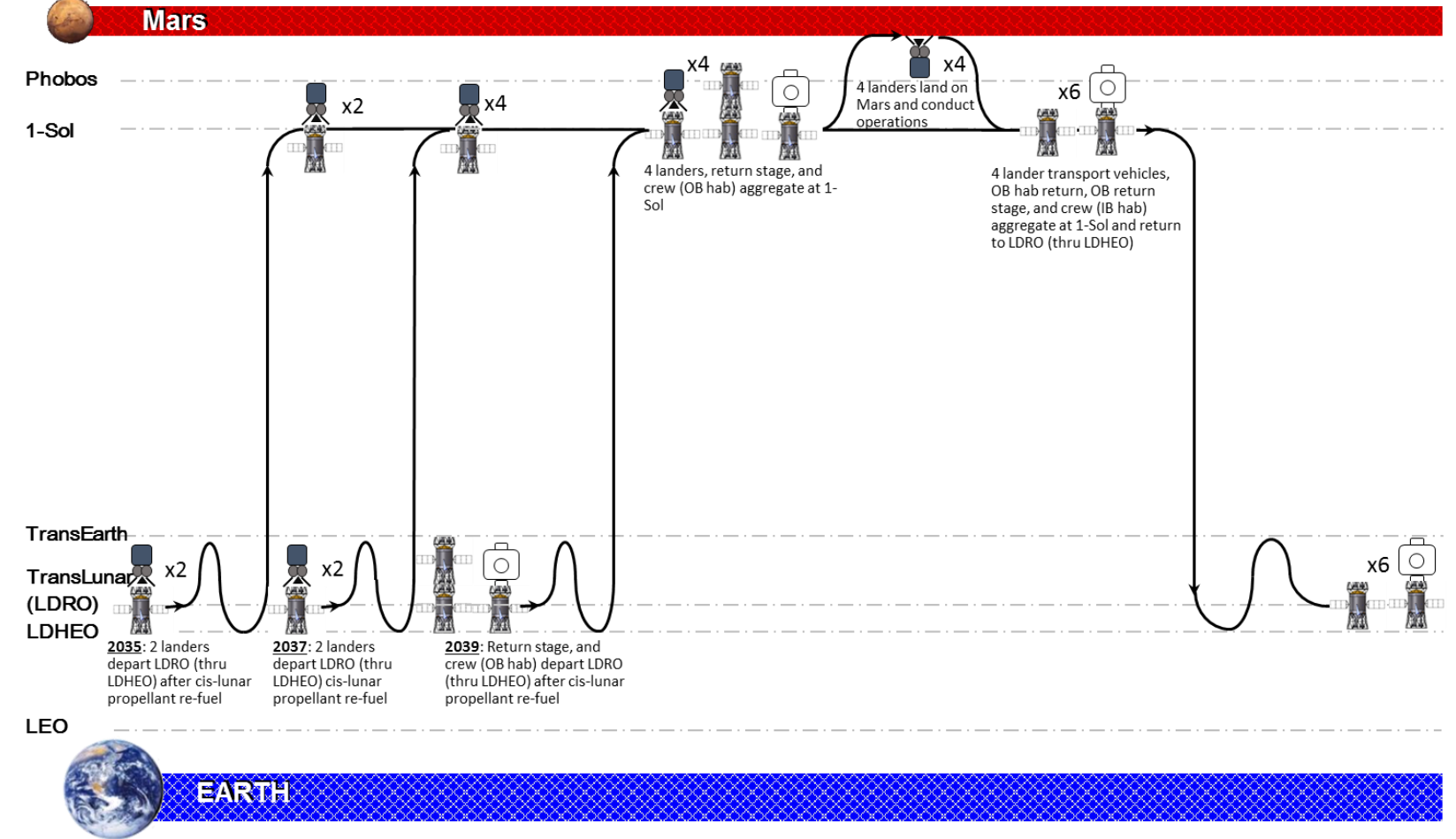

Figure 3. Concept of Operations for 2039 Crewed Mars Surface Mission

In 2039, the transit habitat return stage and transit habitat (crew) depart cis-lunar space, maneuver to the 1-Sol Mars parking orbit, and rendezvous with the pre-deployed lander. The crew land on Mars and conduct mission operations, while the transit habitat reorients itself and prepares for departure. Upon completion of the destination mission, the transit habitat (crew), transit habitat outbound return stage, and four lander in-space stages aggregate back at the Mars parking orbit and return to cis-lunar space.

Figure 4 shows the concept of operations for the 2043 crewed mission to the surface of Mars, including the 2041 cargo mission. Three landers will depart in 2041 and will chemically capture into Mars' sphere of influence, then all three landers descend to the Martian surface in advance of the crewed mission. In 2043, the transit habitat return stage, transit habitat (crew), and an additional lander depart cis-lunar space and maneuver to the 1-Sol Mars parking orbit. The crew land on Mars and conduct mission operations, while the transit habitat reorients itself and prepares for departure. Upon completion of the destination mission, the crew launch back to the parking orbit, aggregate with the transit and transport vehicles, and the transit habitat (crew), transit habitat outbound return stage, and four lander inspace stages return to cis-lunar space. Each subsequent mission in the campaign would follow this concept of operations. 


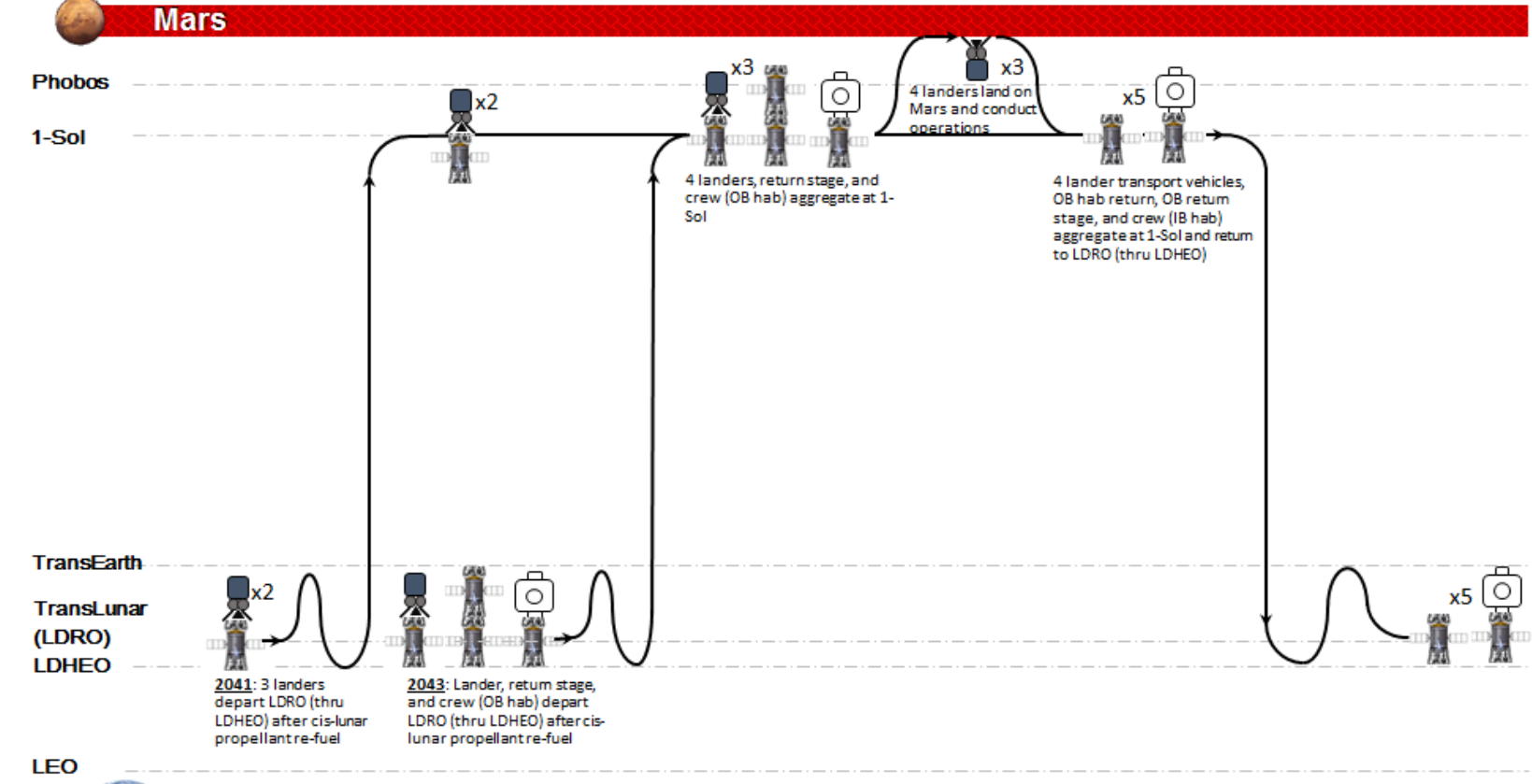

Figure 4. Concept of Operations for 2043 Crewed Mars Surface Mission

\section{Methodology}

\section{A. Flight Element and Payload Data}

To minimize design, development, testing, and evaluation (DDT\&E) costs for a potential in-space transportation element, the all-CP concept implements common element designs across the three crewed mission scenarios evaluated (2033, 2039, and 2043). This single common stage is used with propellant offloading and multiple stages are used to accommodate each mission's performance demands. Propellant requirements are based on an assumption of lossless propellant storage and transfer. CP transportation stages were sized with a variable mass fraction, based on the largest inbound and outbound payloads and $\Delta \mathrm{V}$ s, to show the sensitivity of performance across three propellant combinations for a range of stage mass fractions.

An architecture was considered closed if the requisite stage inert mass was less than 45 tonnes (an estimate of the delivery capability of the SLS through launch cleanup, ballistic lunar transfer, and rendezvous). If the architecture was closed, the propellant requirements of each stage depicted in Figures $2-4$ was then determined. These propellant requirements were used to evaluate the propellant required each year. Propellant storage in cis-lunar space is also assumed; thus, if excess propellant was delivered in one year, it could be used in a future mission. With this assumption and the yearly propellant demands, a minimum propellant requirement per year was computed assuming the first year of delivery was 2030 for the 2031 mission.

Three liquid chemical propulsion propellant options were considered: liquid oxygen (LOX)/liquid hydrogen $\left(\mathrm{LH}_{2}\right)$, LOX/liquid methane $\left(\mathrm{LCH}_{4}\right)$, and nitrogen tetroxide (NTO)/monomethylhydrazine (MMH). $\mathrm{LOX} / \mathrm{LH}_{2}$ and LOX/LCH 4 are cryogenic propellants, while NTO/MMH are hypergolic propellants. Reference values for the specific impulses $\left(\mathrm{I}_{\mathrm{sp}}\right)$ and oxidizer-to-fuel $(\mathrm{O} / \mathrm{F})$ ratios are given in Table $1^{9}$.

Table 1: Propellant Characteristics

\begin{tabular}{|c|c|c|c|c|}
\hline Propellant Type & \multicolumn{1}{|c|}{$\begin{array}{c}\text { O/Fp } \\
\text { Oxidizer Density } \\
\left(\mathrm{kg} / \mathbf{m}^{3}\right)\end{array}$} & $\begin{array}{c}\text { Fuel Density } \\
\left(\mathrm{kg} / \mathbf{m}^{3}\right)\end{array}$ \\
\hline LOX/LH & 450 & 6 & 1,141 & 70.8 \\
\hline LOX/LCH & 360 & 3.5 & 1,141 & 422.4 \\
\hline NTO/MMH & 310 & 2.16 & 1,450 & 880 \\
\hline
\end{tabular}


The payload elements are split into three separate categories: lander, habitat, and Phobos exploration vehicle - the landers and habitats are commonly sized based on maximum expected payload. Figure 5 shows concept artwork for these payload elements (Note: these elements are entirely conceptual and are not representative of actual system designs).

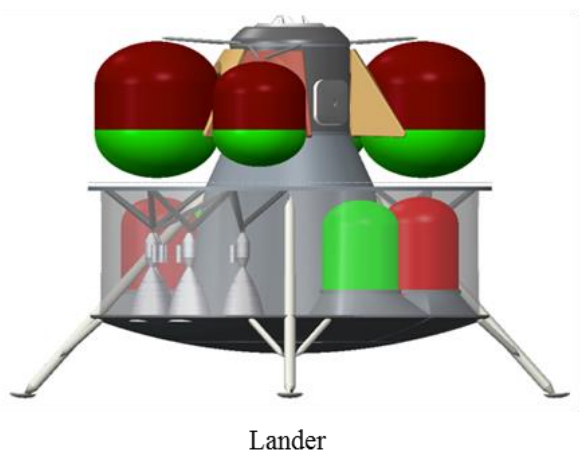

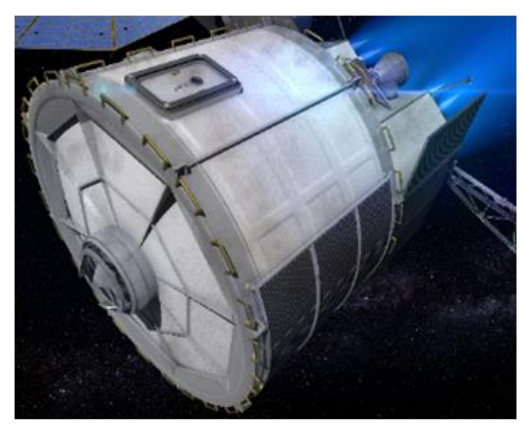

Habitat

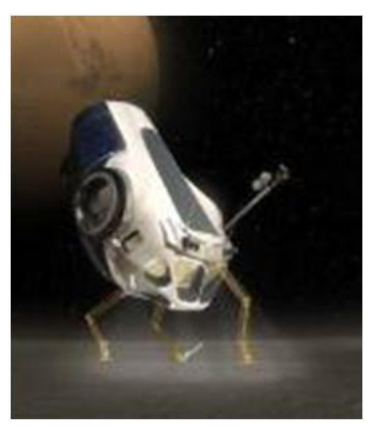

PEV

Figure 5. Representative Payload Designs

In the Evolvable Mars Campaign, Mars surface lander concepts with single HIAD, ascent to 1-Sol orbit and atmospheric in -situ resource utilization for ascent oxidizer are currently estimated to be in the 40-45 $\mathrm{t}$ range with an assumed payload of approximately $20 \mathrm{t}$. Current estimates for long-duration habitat concepts, outfitted with sufficient logistics for the full mission, are also in the 40-45 $\mathrm{t}$ range and are designed for durations of approximately 1100 days. The PEV is used to support the crew during transfer between the transit habitat and Phobos habitat. The mass estimates are presented in Table 2.

Table 2: Payload Data

\begin{tabular}{|c|c|}
\hline Payload Name & Mass $(\mathbf{t})$ \\
\hline Lander & 43.6 \\
\hline Outbound Habitat & 41.2 \\
\hline Inbound Habitat & 37.3 \\
\hline End Habitat & 23.0 \\
\hline PEV & 8.3 \\
\hline Phobos Habitat & 43.0 \\
\hline
\end{tabular}

Habitat masses in Table 2 are based on the estimated mass at three points in the mission as logistics are consumed and waste is removed from the habitat. Outbound begins with the TMI burn, and also includes the MOI and Mars reorientation burns. Inbound begins with the TEI burn, and includes the EOI burn. End is the dry mass of the habitat, assuming all logistics and trash have been removed after the crew transfers to Orion for Earth return, prior to the vehicle's post-crew departure transfer from LDHEO to LDRO. These masses are estimated based on an assumed 1050 day mission for four crew members ${ }^{10,11}$. The maximum crewed mission time from trans-Mars injection to Earth orbit insertion is 994 days (2043 opportunity). This provides additional logistics for Orion rendezvous as well as habitation preparation for dormancy and Earth return. Pre-mission logistics were not included in this analysis because it is assumed that they are included onboard the Orion spacecraft that delivers the crew to LDHEO.

\section{B. Mission Data}

Each mission within the campaign requires multiple cargo missions to be deployed before, or concurrent to, the crewed mission - often, these payloads are deployed in entirely different Mars opportunities than the crew. This is done with the goal of maintaining a consistent number of flights to Mars per opportunity. The campaign assessed includes seven Mars opportunities from 2031-2043 (every 26 months); trajectories for each opportunity include different times of flight and $\Delta \mathrm{V}$ requirements due to variations in the Earth-Mars geometry. Table 3 contains time of flight and $\Delta \mathrm{V}$ for the major maneuvers involved in the crew and cargo missions for minimum energy conjunction class missions. The total time of flight ranges from 951 to 1007 days across this range of opportunities. The major transit $\Delta \mathrm{V}$ requirements listed in Table 3 include the maneuvers for trans-Mars injection and Mars orbit insertion, as well as trans-Earth injection and Earth orbit insertion. The total $\Delta \mathrm{Vs}$ range from 2,800 to 3,200 m/s across the range of 
opportunities. For the Phobos mission, a $1000 \mathrm{~m} / \mathrm{s} \Delta \mathrm{V}$ is assumed for the transfer from 1-Sol to Phobos, and a 1000 $\mathrm{m} / \mathrm{s} \Delta \mathrm{V}$ is assumed for the transfer back. The following $\Delta \mathrm{V}$ requirements were applied to each mission, regardless of opportunity, and are not included in Table 3: $75 \mathrm{~m} / \mathrm{s}$ (each way) from LDRO to LDHEO and back and $300 \mathrm{~m} / \mathrm{s}$ for reorientation of the spacecraft from arrival to departure orbit in the Mars sphere of influence.

Table 3: $\Delta V$ and Time of Flight (TOF) Increments by Opportunity

\begin{tabular}{|c|c|c|c|c|c|}
\hline $\begin{array}{c}\text { Mars } \\
\text { Opportunity }\end{array}$ & $\begin{array}{c}\text { Outbound TOF } \\
\text { (day) }\end{array}$ & $\begin{array}{c}\text { TMI+MOI } \mathbf{\Delta V} \\
(\mathbf{m} / \mathbf{s})\end{array}$ & $\begin{array}{c}\text { Stay Time } \\
\text { (day) }\end{array}$ & $\begin{array}{c}\text { TEI+EOI } \mathbf{\Delta V} \\
(\mathbf{m} / \mathbf{s})\end{array}$ & $\begin{array}{c}\text { Inbound TOF } \\
\text { (day) }\end{array}$ \\
\hline 2031 & 287 & 1,832 & 486 & 1,471 & 218 \\
\hline 2033 & 200 & 1,744 & 553 & 1,554 & 198 \\
\hline 2035 & 201 & 1,444 & 538 & 1,796 & 268 \\
\hline 2037 & 348 & 1,788 & 356 & 1,384 & 285 \\
\hline 2039 & 339 & 1,472 & 342 & 1,411 & 303 \\
\hline 2041 & 318 & 1,352 & 333 & 1,464 & 334 \\
\hline 2043 & 305 & 1,461 & 337 & 1,640 & 352 \\
\hline
\end{tabular}

In addition to the above $\Delta \mathrm{Vs}$ explicitly modeled in this analysis, a margin was applied to all DVs to account for effects not captured in this first order analysis (e.g. reaction control system requirements, mid-course corrections, and thrust buildup). For each combination of propellant type and IMF, margins of $0 \%, 5 \%$, and $10 \%$ were applied to evaluate the impact of the above effects on architectural closure. In addition to this sensitivity, a sensitivity on payload masses was examined; for those assessments, nominal values of IMF and $\Delta \mathrm{V}$ margin were fixed.

\section{Results and Analysis}

The three propellant combinations (NTO/MMH, $\mathrm{LOX} / \mathrm{LCH}_{4}$, and $\mathrm{LOX} / \mathrm{LH}_{2}$ ) were evaluated at IMFs varying from 0.1 to 0.3 . Cases where either the inert mass was greater than 45 tonnes, or where the architecture could not close as defined above, were discarded. Figure 6 shows a comparison of the annual propellant demand among the three chemical propellants, with each subplot corresponding to different values of $\Delta \mathrm{V}$ margin. The break-point (that is, the point at which the architectures as shown in Figures $2-4$ do not close) decreases as the $\Delta \mathrm{V}$ margin increases for all propellant combinations. This analysis assumes that the propellant source is unrestricted; however, the increased propellant demand at LDRO has implications on both the ISRU and Earth propellant delivery options. In the case of ISRU operations, increased demand requires increases in ISRU system mass, spares mass, maintenance, and set-up launches. Similarly for the propellant delivery from Earth to LDRO option, the increased propellant demand requires increased launch rates. 

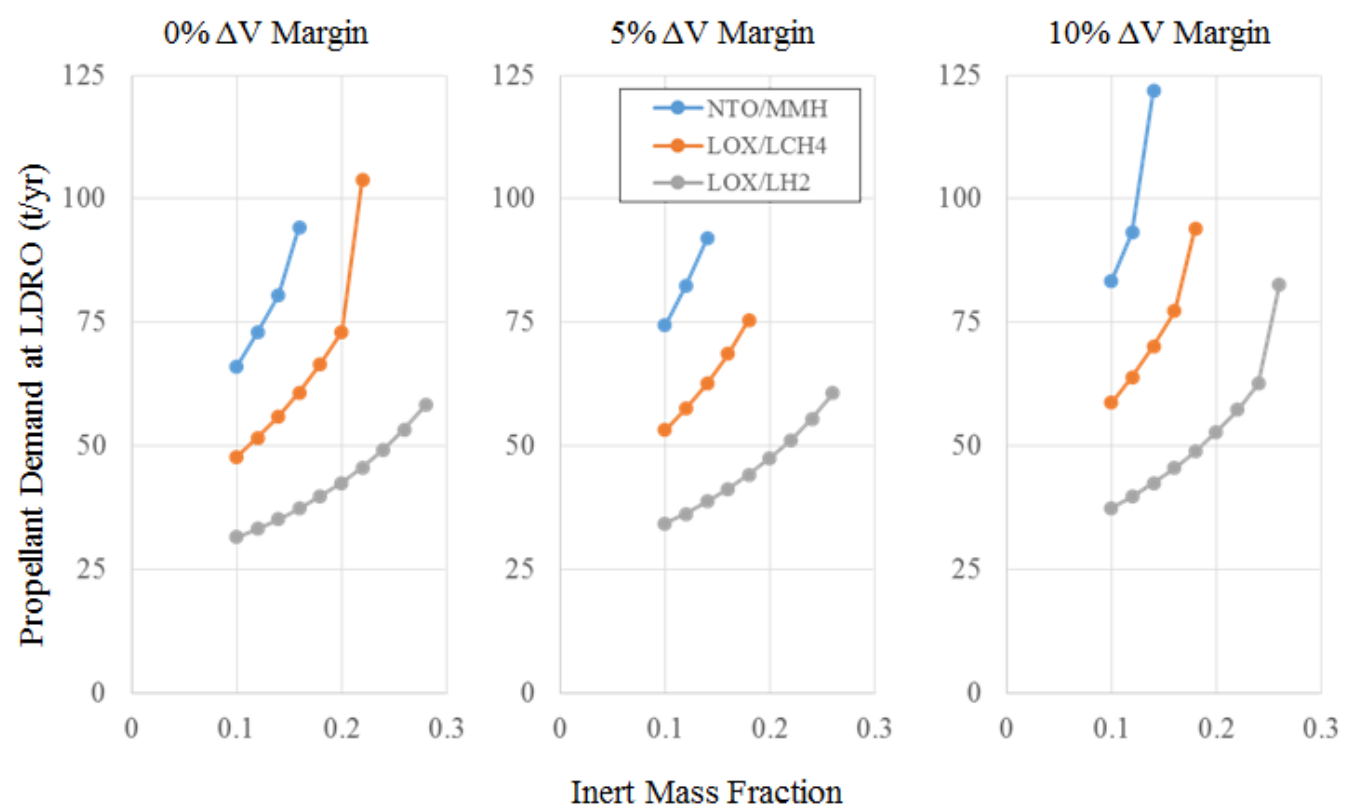

Figure 6. Propellant Comparison with Fixed $I_{s p}$ Penalties and $\Delta V$ Margins

As Figure 6 shows, all three propellant combinations can perform the campaign as described in Figures $2-4$. At a $5 \% \Delta \mathrm{V}$ margin, $\mathrm{NTO} / \mathrm{MMH}$ meets the closure requirements for an IMF equal to or less than 0.14 , requiring between 74 and $92 \mathrm{t} / \mathrm{yr}$ to meet the campaign timeline. By comparison, $\mathrm{LOX} / \mathrm{LCH}_{4}$ closes at an IMF equal to or less than 0.1 , requiring between 53 and $75 \mathrm{t} / \mathrm{yr}$, and $\mathrm{LOX} / \mathrm{LH}_{2}$ closes at an IMF less than or equal to 0.26 , requiring between 34 and $61 \mathrm{t} / \mathrm{yr}$. Table 4 summarizes the maximum IMFs that permit closure, propellant requirement ranges, and stage inert masses for each propellant at the three margins.

Table 4: Annual propellant requirement by propellant type and $\Delta \mathrm{V}$ margin.

\begin{tabular}{|c|c|c|c|c|c|c|}
\hline \multirow{2}{*}{ Propellant } & \multirow{2}{*}{ Margin } & \multirow{2}{*}{ Max IMIF } & \multicolumn{2}{|c|}{ Propellant Requirement (t/yr) } & \multicolumn{2}{|c|}{ Inert Mass $(\mathrm{t})$} \\
\hline & & & IMI $=0.1$ & IMF = Max & $\mathrm{IMF}=0.1$ & IMI = Max \\
\hline NTO/MMH & $0 \%$ & 0.16 & 66 & 94 & 9.3 & 20.8 \\
\hline NTO/MMH & $5 \%$ & 0.14 & 74 & 92 & 10.2 & 16.9 \\
\hline NTO/MMH & $10 \%$ & 0.14 & 84 & 122 & 11.2 & 24.7 \\
\hline $\mathrm{LOX} / \mathrm{LCH}_{4}$ & $0 \%$ & 0.22 & 48 & 104 & 7.1 & 36.6 \\
\hline 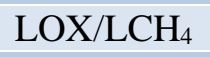 & $5 \%$ & 0.18 & 53 & 76 & 7.7 & 18.6 \\
\hline 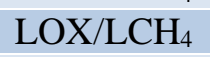 & $10 \%$ & 0.18 & 59 & 94 & 8.4 & 24.2 \\
\hline $\mathrm{LOX} / \mathrm{LH}_{2}$ & $0 \%$ & 0.28 & 32 & 58 & 5.0 & 24.5 \\
\hline $\mathrm{LOX} / \mathrm{LH}_{2}$ & $5 \%$ & 0.26 & 34 & 61 & 5.4 & 23.2 \\
\hline $\mathrm{LOX} / \mathrm{LH}_{2}$ & $10 \%$ & 0.26 & 38 & 83 & 5.8 & 34.8 \\
\hline
\end{tabular}

These results inform both vehicle requirement capabilities and propellant delivery needs. For example, a hydrogenbased transportation architecture would need to be able to develop stages possessing lossless propellant storage at a mass fraction better than 0.28 ( 0.26 with $\Delta \mathrm{V}$ margin). At a lower level of vehicle performance (higher IMF), additional stages would be required to complete the missions requirements. Similarly, without lossless propellant transfer, either the stage would need to be better performing (lower IMF), or additional stages would be needed.

Table 5 shows the propellant required by Mars opportunity for reference cases for each propellant combination. For each combination, there is a peak in propellant requirement for the 2033 opportunity. This results from the need to deliver the PEV and its transfer stage with sufficient propellant for a roundtrip from 1-Sol to Phobos and back, along with the in-space habitat. An additional peak occurs in 2043 due to the delivery of a lander, crew return stage, and in-space habitat. The early peak in propellant demand does not facilitate a build-up in propellant delivery capability, but instead requires the full campaign delivery capability for the first crewed mission. 
Table 5:Propellant requirement by Mars opportunity.

\begin{tabular}{|c|c|c|c|}
\hline Mars Opportunity & $\begin{array}{c}\text { NTO/MMH } \\
@ \text { IMF = 0.1 (t) }\end{array}$ & 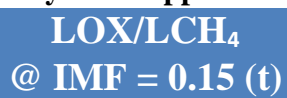 & $\begin{array}{c}\mathrm{LOX}_{\mathbf{L} \mathrm{LH}_{2}} \\
@ \mathrm{IMF}=\mathbf{0 . 2 ( \mathrm { t } )}\end{array}$ \\
\hline 2031 & 92 & 78 & 57 \\
\hline 2033 & 206 & 185 & 133 \\
\hline 2035 & 113 & 105 & 78 \\
\hline 2037 & 130 & 118 & 88 \\
\hline 2039 & 134 & 119 & 87 \\
\hline 2041 & 98 & 91 & 69 \\
\hline 2043 & 203 & 182 & 133 \\
\hline
\end{tabular}

Figure 7 shows the sensitivity of annual propellant demand to changes in the masses of four payloads for each propellant combination. Each payload's reference mass in Table 2 was varied from $-20 \%$ to $+20 \%$ at fixed values of $\mathrm{IMF}$ and $\Delta \mathrm{V}$ margin $\left(\mathrm{IMF}=0.1\right.$ for $\mathrm{NTO} / \mathrm{MMH}, \mathrm{IMF}=0.15$ for $\mathrm{LOX} / \mathrm{LCH}_{4}, \mathrm{IMF}=0.2$ for $\mathrm{LOX}_{\mathrm{LH}}, \Delta \mathrm{V}$ margin $=$ $5 \%$ ). Similar trends are observed at other values of IMF and margin. The Phobos habitat has the most significant impact on propellant demand at LDRO, with percent differences of $+/-12 \%$ for NTO/MMH, $+/-13 \%$ for $\mathrm{LOX}^{-\mathrm{LCH}} 4$ and $+/-13 \%$ for $\mathrm{LOX} \mathrm{LH}_{2}$. Because the common stage sizing is based on the combined effect of payload mass and $\Delta \mathrm{V}$ requirement, the significant impact on the propellant demand indicates that the Phobos habitat, which is the largest payload and requires the most $\Delta \mathrm{V}$ for a single stage, is the driving mission for the stage sizing for the entire campaign. The lander and PEV have almost no impact on propellant demand, as indicated by their respective flat lines in Figure 7. The habitat impacts the propellant demand by $+/-2 \%$ at the $+/-20 \%$ change in payload mass. Examined singularly, the Phobos habitat has the greatest impact on annual propellant demand; a future trade could examine changes in the architecture (e.g. the use of a separate stage for the 1-Sol to Phobos transfer of the habitat) as well as the effect of simultaneous changes in multiple payloads.

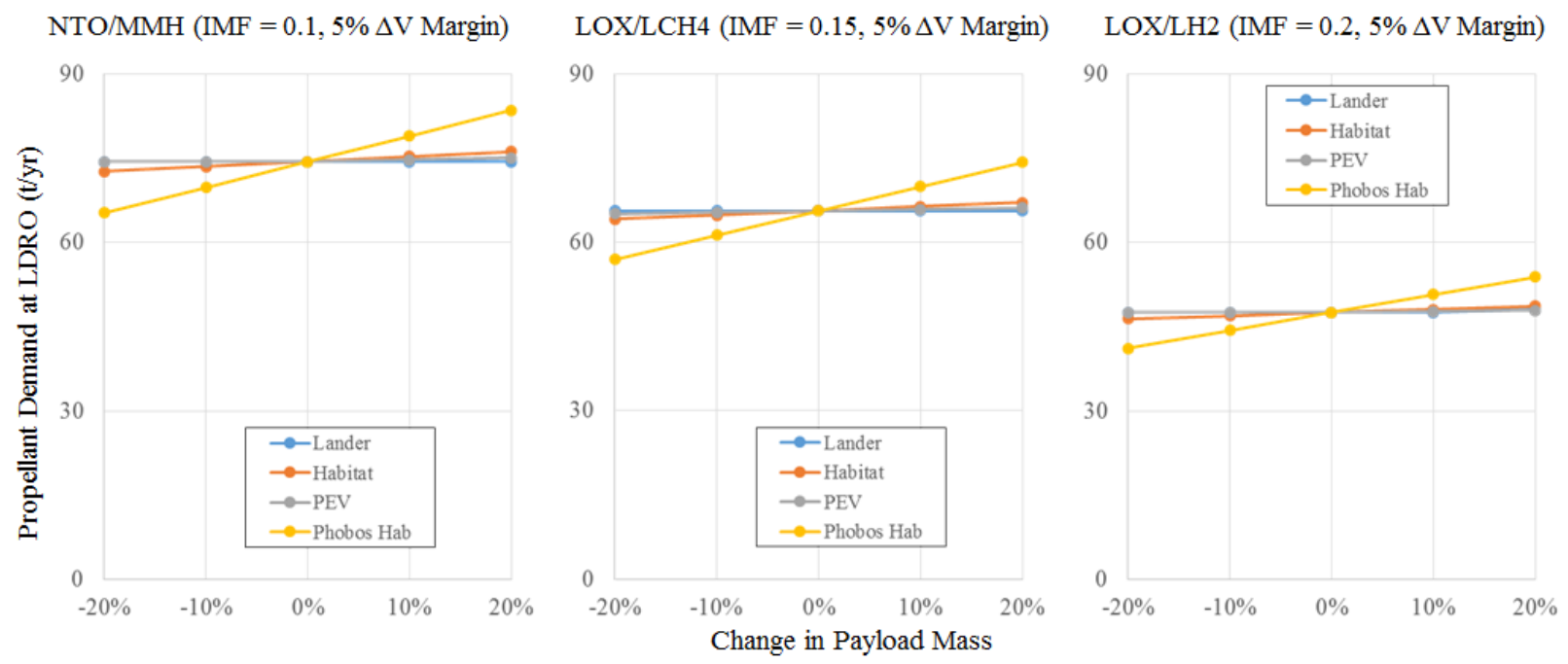

Figure 7. Payload Margin Sensitivity with Fixed Isp Penalty, $\Delta$ V Margin, and IMF

\section{Summary}

Three fuel/oxidizer combinations (NTO/MMH, $\mathrm{LOX}_{\mathrm{LCH}}$, and $\mathrm{LOX} / \mathrm{LH}_{2}$ ) were assessed for this all-chemical propulsion transportation architecture. The annual propellant demand at LDRO was calculated for each propellant combination across a range of IMFs. $\mathrm{LOX} / \mathrm{LH}_{2}$ requires the least propellant per year at each IMF, but detailed vehicle design could show that this option is infeasible due to the increased complexity and mass of the cryogenic fluid management system. Closure of the $\mathrm{LOX} \mathrm{LCH}_{4}$ and NTO/MMH architectures is limited to lower IMF ranges due to their lower specific impulses, but are potentially better options because of their comparatively easier propellant thermal and cryogenic fluid management systems. A future evaluation with more detailed vehicle design would be necessary to evaluate the impacts of developing the systems necessary for propellant management. More detailed system design and corresponding evaluation of technology capabilities for propellant management would inform the 
expected mass fraction of these stages. Under the assumptions of these architectures, all propellant combinations closed. At a $5 \% \Delta \mathrm{V}$ margin, NTO/MMH required up to $92 \mathrm{t} / \mathrm{yr}$, $\mathrm{LOX} / \mathrm{LCH}_{4}$ required up to $75 \mathrm{t} / \mathrm{yr}$, and $\mathrm{LOX} / \mathrm{LH}_{2}$ required up to $59 \mathrm{t} / \mathrm{yr}$.

Several factors in future analysis will impact these propellant requirements. Losses from propellant storage and transfer were not modeled; a future trade between the technology requirements to minimize propellant loss and the mass and power of those systems can be evaluated. In addition, losses from propellant transfer will increase the required annual delivery. Additionally, changes in the campaign manifest and start date for propellant delivery could reduce the annual propellant requirements, as the initial Phobos mission drives the vehicle sizing and thus has a significant impact on the campaign propellant needs. The results of this research inform the implementation of a cislunar chemical refueling transportation architecture, particularly the propellant demand at LDRO from either Earth or inner solar system sources.

\section{Acknowledgments}

The authors would like thank the Systems Analysis and Concepts Directorate at NASA Langley Research Center for funding this study.

\section{References}

1. Goodliff, K., Troutman, P., Craig, D., and Herrmann, N., "Evolvable Mars Campaign 2016 Analysis Update,” 2016 AIAA Space Conference, Long Beach, CA, September 2016.

2. Merrill, R., Chai, P., and Qu, M., "An Integrated Hybrid Transportation Architecture for Human Mars Expeditions," AIAA SPACE 2015 Conference and Exposition, Pasadena, CA, 2015.

3. Betzendahl, R., "Ever Changing Rare Gas Market," CryoGas International, February 2013, from http://ntrs.nasa.gov/archive/nasa/casi.ntrs.nasa.gov/20150023080.pdf, accessed July 18, 2016.

4. Ishimatsu, T., De Weck, O., Hoffman, J., Ohkami, Y., and Shishko, R. "Generalized Multicommodity Network Flow Model for the Earth-Moon-Mars Logistics System”, Journal of Spacecraft and Rockets, Vol. 53, No. 1 (2016), pp.25-38.

5. Gaebler, J., Lugo, R., Axdahl, E., Chai, P., Grimes, M., Long, M., Rowland, R., and Wilhite, A. "Reusable Lunar Transportation Architecture Utilizing Orbital Propellant Depots," AIAA SPACE 2009 Conference and Exposition, Pasadena, CA, 2009.

6. Jones, C., Brown, C., and Wilhite, A., "Utilization of Lunar Resources for Human Mars Missions," AIAA SPACE 2011 Conference and Exposition, Long Beach, CA, 2011.

7. Wilhite, A., Chai, P., Currey, S., Jones, C., Noevere, A., and Rossman, G., "The Utilization of Launch Vehicle Core Stages and Propellant Depots for Human Space Exploration," 49 ${ }^{\text {th }}$ AIAA/ASME/SAE/ASEE Joint Propulsion Conference, San Jose, CA, 2013.

8. Drake, B., "Human Exploration of Mars: Design Reference Architecture 5.0," NASA/SP-2009-566.

9. Humble, R. W., Henry, G. N., Larson, W. J., "Rocket Fundamentals," Space Propulsion Analysis and Design, 1st ed., Vol. 1, McGraw-Hill, New York, NY, 1995.

10. Lopez, P, Schultz, E., Mattfeld, B., Stromgren, C., and Goodliff, K., "Logistics Needs for Potential Deep Space Mission Scenarios Post Asteroid Redirect Crewed Mission,” 2015 IEEE Aerospace Conference, Big Sky, MT, 2015.

11. Stromgren, C., Terry, M., Cirillo, W., Goodliff, K. and Maxwell, A., "Design and Application of the Exploration Maintainability Analysis Tool," AIAA Space 2012 Conference and Exposition, AIAA-2012-5323, Pasadena, CA, September 2012.

12. Sanders, G.B. "In-Situ Resource Utilization of Mars - Update from DRA 5.0 Study." $48^{\text {th }}$ AIAA Aerospace Sciences Meeting. 2010. 